\title{
Evaluation of infratentorial atrophy by computed tomography
}

\author{
DETLEF CLAUS, JÜRGEN C ASCHOFF \\ From the Department of Neurology, University of Ulm, Ulm, W Germany
}

SUMMARY Eight parameters of cranial computed tomograms were examined from 121 controls, 33 patients suffering from paleocerebellar atrophy and 53 with widespread cerebellar atrophy. With the aid of step-by-step linear discriminant analysis the most important parameters were found and their normal and limiting values were calculated. With the help of correlation analysis the correlation between normal values and the age of the controls was investigated.

For the evaluation of pneumoencephalographic and CT images of infratentorial atrophy various parameters have been used to distinguish the normal from the pathological. We present a study which reconsiders these parameters and introduces statistically proven standards.

\section{Method and material}

CT images (Siretom $2000 ; 256 \times 256$ pixels; gantry $20^{\circ}$ ) of 121 persons ( 49 male, 72 female, average age 36 years) were used as controls. Headaches, minor fits, minor head injuries, or depression were the reasons for CT investigation. No clinical signs could be detected on neurological examination. The CTs of controls were compared with those of 86 patients with clinical signs of cerebellar pathology. According to the clinical data ${ }^{1}$ the group consisted of those with late cerebellar atrophy (18 patients), cerebellar atrophy due to alcoholism (14 patients), due to phenytoin (five patients), of paraneoplastic origin (five patients), vitamin B12 deficiency (one), and 10 cases of uncertain cause. Also included were 27 patients suffering from Friedreich's ataxia, three patients with Nonne-Marie's syndrome, and three patients with olivoponto cerebellar atrophy. The CT diagnosis of paleocerebellar atrophy was made in 23 male and 10 female patients (average age 36 years), whereas widespread cerebellar atrophy (53 patients) occurred in 30 male and 23 female patients (average age 51 years).

For the diagnosis of infratentorial atrophy we recommended in a recent publication ${ }^{2}$ parameters such as

Address for reprint requests: Dr D Claus, Department of Neurology, Medical High School of Lübeck, Ratzeburger Allee 160, D24 Lübeck, West Germany.

Received 12 April 1982 and in revised form 26 July 1982. Accepted 9 August 1982 the visualisation of four or more vermal sulci, two or more cerebellar hemispheric sulci, a fourth ventricle diameter of more than $20 \mathrm{~mm}^{3}$ and the subjective impression of the width of cerebellar-pontine angle and other infratentorial cisterns. For further classification and increased objectivity all CT scans (10 mm slice) were re-evaluated. This included counting the number of clearly visible vermal and overall cerebellar sulci, measuring diameters of the 4th ventricle, pons, cisterna magna, and cerebello-pontine angle cistern (according to ref 1). In addition, calculations were made of the upper vermal index and fourth ventricular index ${ }^{1}$ as shown in fig 1 . The upper vermal index ${ }^{2}$ was calculated by dividing the diameter of the rostral upper vermal cistern measured where it bordered on the quadrigeminal cistern by the largest inner skull diameter, the latter being measured on the same CT scan. The $95 \%$ confidence range for all variables was calculated according to the formula

$95 \%$ confidence range $=\bar{x} \pm K \cdot S D$

$$
\left(K=t_{2} \text { alpha,n-1 } \times \sqrt{\frac{1}{n}}\right)
$$

and on the assumption that this was normal variation (Z-score symmetrical, variation coefficiency under $30 \%$ ). Percentiles were used for definition of limiting values. The influence of age was investigated by means of correlation analysis. Evaluation of the importance of the different parameters was done by step-by-step linear discriminance analysis.

\section{Results}

As shown in table 1, in the control group with its age range from 1 to 71 years, four vermal sulci were seen only once, in a 50-year-old female, and two cerebellar hemispheric sulci twice (in a 39-year-old female, and a 62-year-old male).

Upper vermal index values in cases of cerebellar atrophy have been consistently above index values of controls; this, also, was found for the fourth 

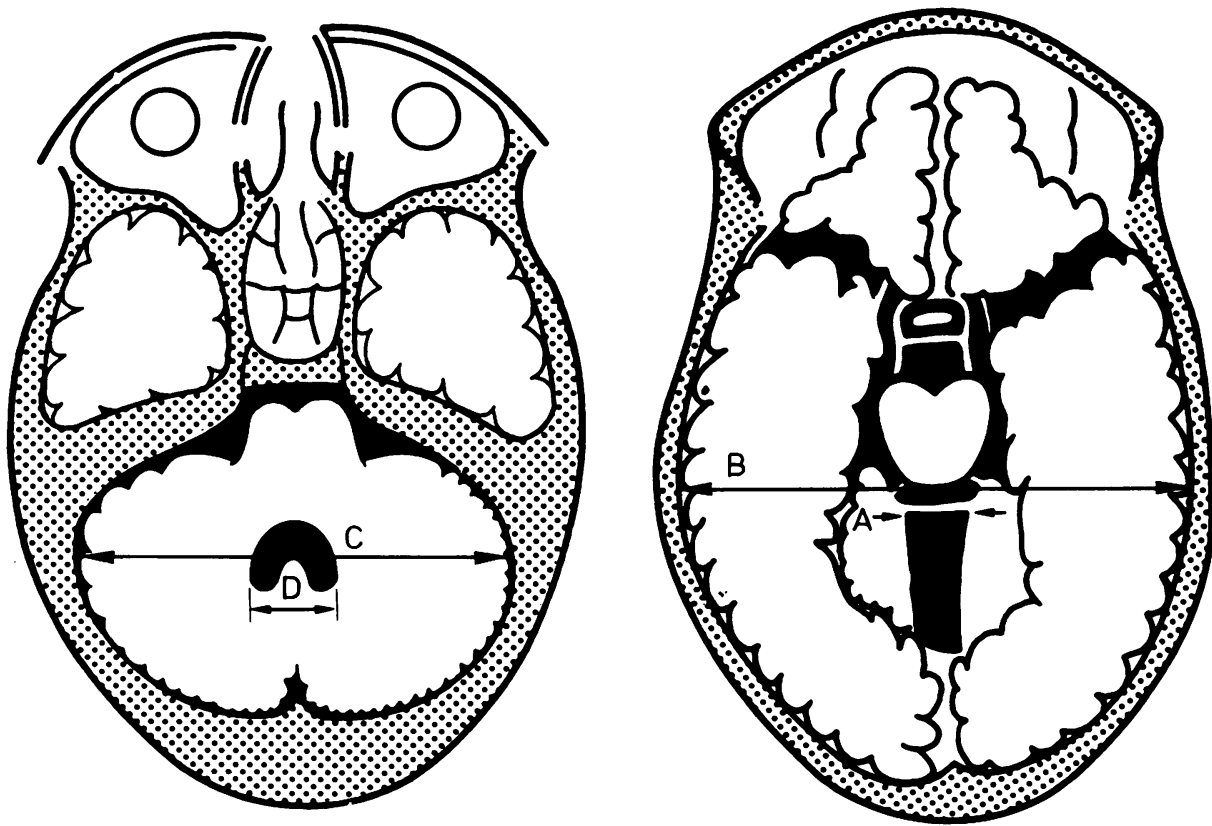

Fig: $1 \frac{A}{B}=$ upper vermal index, $\frac{D}{C}=$ fourth ventricle index $^{2}$

Table 1 Mean values, standard deviation, and confidence intervals of the 8 investigated parameters

\begin{tabular}{|c|c|c|c|c|}
\hline & & $\begin{array}{l}\text { Controls } \\
(n=121)\end{array}$ & $\begin{array}{l}\text { Paleocerebellar } \\
\text { atrophies } \\
(n=33)\end{array}$ & $\begin{array}{l}\text { Ubiquitous cerebellar } \\
\text { atrophies } \\
(n=53)\end{array}$ \\
\hline $\begin{array}{l}\text { Vermal sulci } \\
\left(X_{i}(0-6)\right.\end{array}$ & $\overline{\mathrm{X}}$ & $\begin{array}{l}1 \cdot 36 \\
\left(17 \times x_{i}=3\right)\end{array}$ & $4 \cdot 06$ & $4 \cdot 23$ \\
\hline $\begin{array}{l}\text { Cerebellar hemispheric sulci } \\
\left(\mathrm{X}_{\mathrm{i}}(0-5)\right.\end{array}$ & $\bar{x}$ & $\begin{array}{r}0 \cdot 19 \\
\left(17 \times X_{i}=1\right) \\
\left(2 \times X_{i}=2\right)\end{array}$ & $0 \cdot 49$ & $2 \cdot 42$ \\
\hline \multirow[t]{2}{*}{ Upper vermal index } & $\begin{array}{l}\bar{X} \\
95 \% \text { confidence interval for } \bar{X}\end{array}$ & $\begin{array}{l}0 \cdot 162 \\
0 \cdot 158-0 \cdot 166\end{array}$ & $0 \cdot 190$ & $0 \cdot 185$ \\
\hline & $\begin{array}{l}\text { SD } \\
\text { SEM }\end{array}$ & $\begin{array}{l}0.02 \\
0.002\end{array}$ & $\begin{array}{l}0 \cdot 03 \\
0 \cdot 004\end{array}$ & $\begin{array}{l}0.02 \\
0.003\end{array}$ \\
\hline \multirow[t]{2}{*}{ Ventricle IV-index } & $\begin{array}{l}\bar{X} \\
95 \% \text { confidence interval for } \bar{X}\end{array}$ & $\begin{array}{l}0 \cdot 137 \\
0 \cdot 133-0 \cdot 141\end{array}$ & $0 \cdot 157$ & $0 \cdot 163$ \\
\hline & $\begin{array}{l}\text { SD } \\
\text { SEM }\end{array}$ & $\begin{array}{l}0.02 \\
0.002\end{array}$ & $\begin{array}{l}0.03 \\
0.005\end{array}$ & $\begin{array}{l}0.04 \\
0.005\end{array}$ \\
\hline \multirow[t]{2}{*}{ Fourth ventricle diameter (mm) } & $\begin{array}{l}\bar{X} \\
95 \text { confidence interval for } \bar{X}\end{array}$ & $\begin{array}{l}14 \cdot 54 \\
14 \cdot 2-14 \cdot 4\end{array}$ & $16 \cdot 71$ & 16.91 \\
\hline & $\begin{array}{l}\text { SD } \\
\text { SEM }\end{array}$ & $\begin{array}{l}2 \cdot 18 \\
0 \cdot 20\end{array}$ & $\begin{array}{l}2 \cdot 93 \\
0 \cdot 51\end{array}$ & $\begin{array}{l}3 \cdot 71 \\
0.51\end{array}$ \\
\hline Cerebello-pontine angle cistern $(\mathrm{mm})^{*}$ & $\begin{array}{l}\mathrm{X} \\
\text { SD } \\
\text { SEM }\end{array}$ & $\begin{array}{l}4 \cdot 10 \\
2 \cdot 01 \\
0 \cdot 18\end{array}$ & $\begin{array}{l}6 \cdot 10 \\
2 \cdot 73 \\
0 \cdot 48\end{array}$ & $\begin{array}{l}6 \cdot 80 \\
2 \cdot 50 \\
0 \cdot 34\end{array}$ \\
\hline Pons diameter (mm) & $\begin{array}{l}\mathbf{X} \% \text { confidence interval for } \bar{X} \\
\end{array}$ & $\begin{array}{l}32 \cdot 20 \\
31 \cdot 6-32 \cdot 7\end{array}$ & $33 \cdot 10$ & $32 \cdot 50$ \\
\hline Cisterna magna diameter $(\mathrm{mm})^{*}$ & $\begin{array}{l}\text { SD } \\
\text { SEM } \\
\text { SD } \\
\text { SEM }\end{array}$ & $\begin{array}{l}2 \cdot 88 \\
0 \cdot 26 \\
5 \cdot 8 \\
6 \cdot 03 \\
0 \cdot 55\end{array}$ & $\begin{array}{l}3 \cdot 83 \\
0 \cdot 67 \\
6 \cdot 2 \\
6 \cdot 07 \\
1 \cdot 06\end{array}$ & $\begin{array}{l}3 \cdot 76 \\
0 \cdot 52 \\
7 \cdot 8 \\
7 \cdot 33 \\
1 \cdot 01\end{array}$ \\
\hline
\end{tabular}

${ }^{*}$ asymmetrical distribution. 
ventricular index. Fourth ventricle diameter in controls had an average width of $14.5 \mathrm{~mm}$, whereas mean diameters of about $17 \mathrm{~mm}$ were measured in the group of paleocerebellar and of global cerebellar atrophies.

The average diameter of cerebello-pontine angle cisterns (between the two sides always the larger one was taken) increased from $4.1 \mathrm{~mm}$ in the control group to $6.8 \mathrm{~mm}$ in the global atrophy group. For the diameter of the pons, a similar relationship could not be detected. The average diameter of the cisterna magna increased from $5.8 \mathrm{~mm}$ in controls to $7.8 \mathrm{~mm}$ in cerebellar atrophy. Diameters varied between 0 and $25.7 \mathrm{~mm}$ in controls, 0 and $21.5 \mathrm{~mm}$ in paleocerebellar, and 0 to $33.7 \mathrm{~mm}$ in global cerebellar atrophy. Large standard deviations resulted from this variability.

The numbers of visible vermal sulci and cerebellar hemispheric sulci were age-independent. Three vermal sulci were seen in persons aged 12 to 69 years, and one hemispheric cerebellar sulcus in persons aged 20 to 70 years, with equal distributions between the age groups. Fourth ventricle diameter (correlation coefficient $r=-0.052$ ), cerebello-pontine angle cistern $(r=0.089)$ and fourth ventricle indices $(r=$ $-0.087)$ were age-independent. Only the diameter of the pons $(r=0 \cdot 377)$ increased slightly with age, whereas the variability of the cisterna magna diameters decreased in $12 \%(\mathrm{r}=-0.344)$ of controls. Both correlations are against logical expectation. A minor age dependency $(r=0 \cdot 192$; $p=0.05$ ) was seen in $4 \%$ of upper vermal indices. This correlation can be neglected, because increase of regression line is minimal $\left(y=226 \cdot 10^{-6} x+\right.$ $0 \cdot 15344)$.
Within the control group no differences could be detected between the sexes for all measured and calculated parameters. Average values are listed below:

Upper vermal index $\begin{array}{cc}\text { Male } & \text { Female } \\ 0 \cdot 162 & 0 \cdot 161 \\ 0 \cdot 140 & 0 \cdot 134\end{array}$

Fourth ventricle index

Diameter of fourth ventricle

Diameter of cerebello-pontine angle cistern

Diameter of pons

Diameter of cisterna magna The validity of the eight parameters was investigated with a step-by-step linear discriminance analysis (table 2). This lead to the conclusion that in paleocerebellar atrophy counting of visible vermal sulci, and also the upper vermal and fourth ventricle indices are optimal parameters for separation of the normal from the pathological. In spite of its large variability the diameter of the cerebello-pontine angle cistern is also useful in some cases. For discrimination purposes, 2.7 vermal sulci were calculated, and this confirms the limiting value of three sulci from the first index. The counting of cerebellar hemispheric sulci (the calculated discrimination value of 1.3 confirms the upper limit of one sulcus), the number of vermal sulci, and the upper vermal index are effective in diagnosing global cerebellar atrophy.

For the purpose of discriminating between the controls and both groups of cerebellar atrophy simultaneously, the counting of vermal and of cerebellar hemispheric sulci, upper vermal index, and fourth ventricle diameter gave the best results. To discriminate between the three groups simul-

Table 2 Percentage of correct classification into the three different groups by stepwise linear discriminant analysis

\begin{tabular}{|c|c|c|c|}
\hline & \multicolumn{3}{|c|}{ Percentage of correct classification into group of } \\
\hline & controls & atrophies & overall correct judgment \\
\hline $\begin{array}{l}\text { Controls }(n=121) \text { versus } \\
\text { Paleocerebellar } \\
\text { Atrophies }(n=33) \\
\text { number of vermal sulci only } \\
\text { in addition: upper vermal index } \\
\text { in addition: fourth ventricle index } \\
\text { in addition: cerebello-pontine angle cistern }\end{array}$ & $\begin{array}{l}84 \cdot 3 \\
90 \cdot 9 \\
92 \cdot 6 \\
95 \cdot 0\end{array}$ & $\begin{array}{r}97 \cdot 0 \\
97 \cdot 0 \\
100 \cdot 0 \\
100 \cdot 0\end{array}$ & $\begin{array}{l}87 \cdot 0 \\
92 \cdot 2 \\
94 \cdot 2 \\
96 \cdot 1\end{array}$ \\
\hline $\begin{array}{l}\text { Controls }(n=121) \text { versus } \\
\text { Ubiquitous cerebellar } \\
\text { Atrophies }(n=53) \\
\text { number of cerebellar hemispheric sulci only } \\
\text { in addition: number of vermal sulci } \\
\text { in addition: upper vermal index }\end{array}$ & $\begin{array}{l}98 \cdot 3 \\
98 \cdot 3 \\
99 \cdot 2\end{array}$ & $\begin{array}{l}100 \cdot 0 \\
100 \cdot 0 \\
100 \cdot 0\end{array}$ & $\begin{array}{l}98 \cdot 9 \\
98 \cdot 9 \\
99 \cdot 4\end{array}$ \\
\hline $\begin{array}{l}\text { Controls versus all cerebellar } \\
\text { Atrophies }(n=86) \\
\text { number of vermal sulci only } \\
\text { in addition: number of cerebellar hemispheric sulci } \\
\text { in addition: upper vermal index } \\
\text { in addition: fourth ventricle diameter }\end{array}$ & $\begin{array}{l}84 \cdot 3 \\
92 \cdot 6 \\
92 \cdot 6 \\
95 \cdot 0\end{array}$ & $\begin{array}{r}98 \cdot 8 \\
98 \cdot 8 \\
100 \cdot 0 \\
98 \cdot 8\end{array}$ & $\begin{array}{l}90 \cdot 3 \\
95 \cdot 2 \\
95 \cdot 7 \\
96 \cdot 6\end{array}$ \\
\hline
\end{tabular}




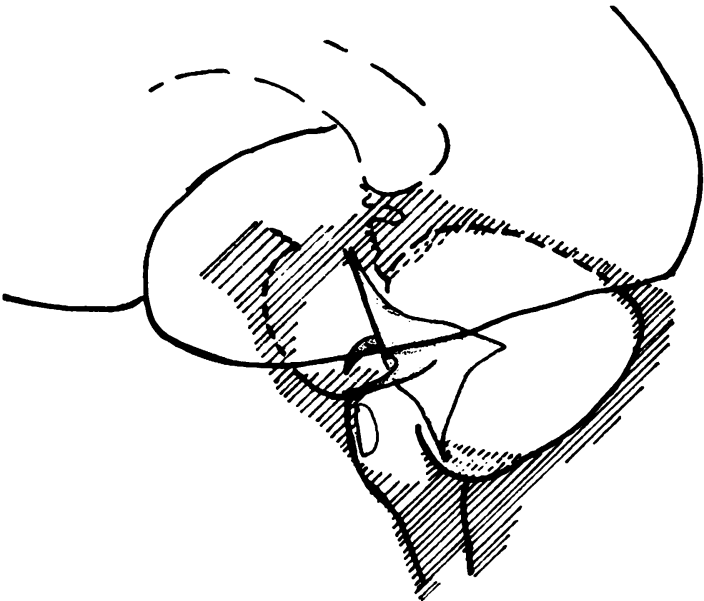

Fig 2 Schematic lateral view of the posterior fossa structures showing the complicated configuration of the cisterns (hatched).

taneously three parameters were the most effective: the cerebellar hemispheric sulci, the vermal sulci, and the upper vermal index.

\section{Discussion}

Figure 2 shows a lateral view of the complicated posterior fossa structures. It shows that the shape and size of these structures on the CT slice depend largely on the gantry and section position. The convex shaped upper cerebellum is least altered, unlike the cisterns around the lower brainstem and lower brainstem itself. Therefore distortions make the measurement of areas and volumes very inaccurate on CT slices. Hence, it is important to use only those parameters which are easily measured and are reliable (table 3 ). These now will be discussed in order of importance.

Counting of clearly visible vermal sulci on one CT slice was very practicable ${ }^{4}$ particularly in global cerebellar atrophy which seldom spares the upper vermis. ${ }^{15}$ Seventeen of the 121 control CT scans showed three vermal sulci. This number, therefore, is a good upper limiting value, not one or two vermal sulci. $^{6-9}$ The measuring of vermal sulci diameters, which could be done by pneumoencephalography very well, ${ }^{5}$ could be carried out only inaccurately with contemporary CT.

Cerebellar hemispheric sulci were very helpful in

Table 3 Normal and limiting values (121 controls)

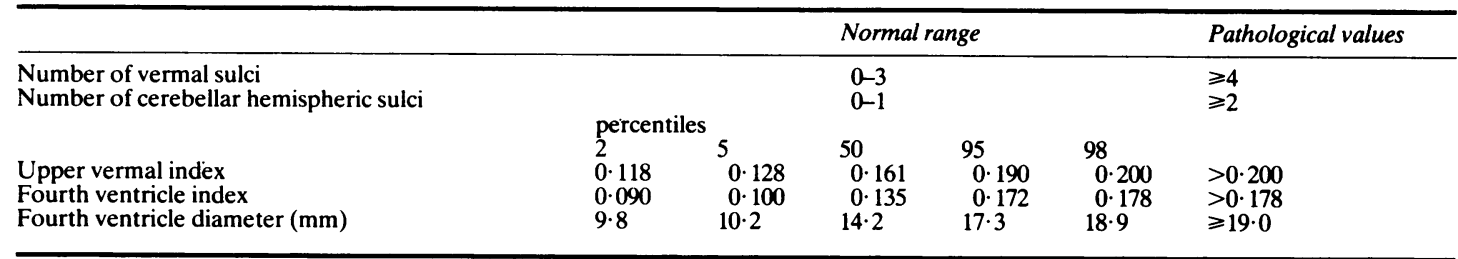

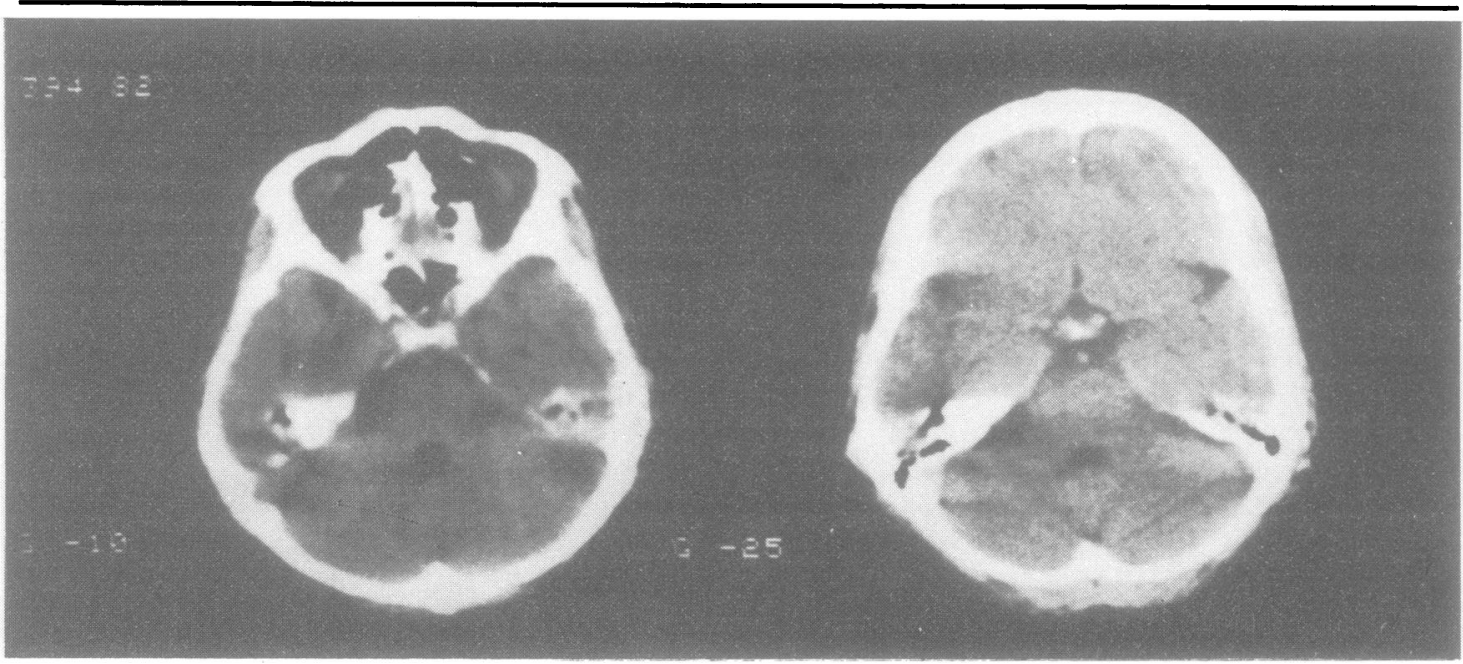

Fig: 3 Two CT scans of the same patient showing that the diameters of pons, cerebello-pontine angle cistern, and fourth ventricle vary by tilting the gantry from $-10^{\circ}$ to $-25^{\circ}$. 
diagnosing global cerebellar atrophy. Only sulci which are clearly seen across the whole upper cerebellar hemisphere should be counted, but not lateral dents (see fig 3). We found one cerebellar hemispheric sulcus (over one or both hemispheres) in 17 of the 121 control CT scans. Therefore, one sulcus $^{78}$ is not pathological but two clearly visible sulci can be taken to be a sign of atrophy. ${ }^{69}$

The upper vermal index ${ }^{2}$ was effective for all kinds of cerebellar atrophies (see table 2). This was shown by Koller too, ${ }^{8}$ but with different normal values achieved by different methods.

The fourth ventricular index was less effective because the shape and diameter of the fourth ventricle (counted without the lateral recess) are influenced by position (see fig 3). Moreover, the fourth ventricle is not dilated in all cerebellar atrophies $^{459}$ and its enlargement alone does not indicate cerebellar atrophy. Nevertheless the index, which was counted in a similar way by Koller and others $^{810}$ improved the diagnosis of paleocerebellar atrophies.

For the fourth ventricle diameters of $23 \mathrm{~mm}^{11}$ and $20 \mathrm{~mm}^{3}$ have been found by pneumoencephalography for upper limit values. By computed tomography diameters of 12 to $16 \mathrm{~mm}$ were classified as slight and more than $16 \mathrm{~mm}$ as distinct thickening. ${ }^{12}$ We found a 95th percentile of $17 \mathrm{~mm}$ and a 98th percentile of $19 \mathrm{~mm}$ in our control group.

The diameter of cerebello-pontine angle cistern is influenced by the patient's head position (fig 3). Nevertheless it helped in the diagnosis of a few cases of paleocerebellar atrophy. Because of its great variability (see table 1) there is nothing to be gained by defining limiting values for this parameter.

The range of the diameter of the ellipsoidal shaped pons depends on the position and gantry of the CT section. Therefore, it was not used in the discriminance analysis and there was no correlation between the diameter of the pons and the cerebellopontine angle cistern $(\mathrm{r}$ controls $=0.162, \mathrm{r}$ paleocerebellar atrophy $=0 \cdot 083, \mathrm{r}$ global atrophy $=$ $-0 \cdot 112$ ).

It was not possible to distinguish between the cerebello-medullary cistern and the inferior vermal cistern clearly. Its diameter depends on the gantry and on the level of the section. It gave no information ${ }^{911}$ about cerebellar atrophies.

Four parameters were sufficient to estimate the cerebellar atrophies by computed tomography. These are the counting of vermal and cerebellar hemispheric sulci, the upper vermal index, and the fourth ventricular index, or instead of this, the diameter of fourth ventricle itself. The measuring of further parameters did not improve the effectiveness. It was better to estimate the complicated shaped structures like pons, cerebello-pontine angle cistern, prepontine cistern, or cerebellomedullary cistern subjectively,,$^{5781314^{-}}$taking the form, size and relationships to each other, into account.

\section{References}

' Claus D, Aschoff JC. Computertomographische Differentialdiagnose infrantentorieller Atrophien. Arch Psychiat Nervenkr 1982;231:289-303.

${ }^{2}$ Claus D, Aschoff JC. Computer-Tomografie bei Atrophien im Bereich der hinteren Schädelgrube. Arch Psychiat Nervenkr 1980;229:179-187.

${ }^{3}$ Taveras JM, Wood EH. Diagnostic Neuroradiology. 2nd ed. Vol. 1. Baltimore: Williams \& Wilkins.

${ }^{4}$ LeMay M, Abramowicz A. The pneumoencephalographic findings in various forms of cerebellar degeneration. Radiology 1965;85:284-90.

${ }^{5}$ Kennedy P, Swash M, Wylie IG. The clinical significance of pneumographic cerebellar atrophy. $\mathrm{Br} J$ Radiol 1976;49:903-11.

${ }^{6}$ Lee SH, Altamarino LS, Toglia JU. Cerebellar atrophy: pneumoencephalography and computerized tomography correlation. Neuroradiology 1978;16:179-80.

${ }^{7}$ Haubek A, Lee K. Computed tomography in alcoholic cerebellar atrophy. Neuroradiology 1979;18:77-9.

${ }^{8}$ Koller WC, Glatt SL, Perlik S, Huckman MS, Fox JH. Cerebellar atrophy demonstrated by computed tomography. Neurology (Ny) 1981;31:405-12.

9 Allen JH, Martin JT, McLain LW. Computed tomography in cerebellar atrophic processes. Radiology 1979;130:379-82.

${ }^{10}$ Maruyama S, Okayama K, Aikawa T, Saito Y, Nobayashi N. CT scan study of spinocerebellar degeneration. Pp. 67-82 in: Itsuro Sobue (ed.) Spinocerebellar degenerations. Tokyo: University of Tokyo Press, 1980.

" Strecker EP, Hodges FJ, James AE. Cerebellar atrophy: a cisternographic and pneumoencephalographic analysis. Am J Roentgenol 1972;115:760-5.

${ }^{12}$ Meese W, Grumme Th. Die Beurteilung hirnatrophischer Prozesse mit Hilfe der Computertomographie. Fortschr Neurol 1980;48:495509.

13 Avdaloff W, Mauersberger W. Über die frühen Symptome der Kleinhirnatrophie bei chronischem Alkoholismus. Nervenarzt 1981;52:333-9.

${ }^{14}$ Langelier R, Bouchard JP, Bouchard R. Computed tomography of posterior fossa in hereditary ataxias. $J$ Can Sci Neurol 1979;6:195-8. 